\title{
From the accidental to articulated smart city: The creation and work of 'Smart Dublin'
}

European Urban and Regional Studies 2019, Vol. 26(4) 349-364 (C) The Author(s) 2018 Article reuse guidelines: sagepub.com/journals-permissions DOI: $10.1177 / 0969776418785214$ journals.sagepub.com/home/eur @SAGE

\section{Claudio Coletta, Liam Heaphy and Rob Kitchin}

Maynooth University, Ireland

\begin{abstract}
While there is a relatively extensive literature concerning the nature of smart cities in general, the roles of corporate actors in their production and the development and deployment of specific smart city technologies, to date there have been relatively few studies that have examined the situated practices by which the smart city unfolds in specific places. In this paper, we draw on three sets of interviews $(n=114)$ and ethnographic fieldwork to chart the smart city ecosystem in Dublin, Ireland. We examine how the four city authorities have actively collaborated to frame a disparate and uncoordinated set of information and communication technology-led initiatives, what Dourish terms the 'accidental smart city', into an articulated vision of Dublin as a smart city. In particular, we focus on the work of 'Smart Dublin', a shared unit established to coordinate, manage and promote Dublin's smart city initiatives and to drive new economic development opportunities centred on corporate interventions into urban management and living. Our analysis highlights the value of undertaking a holistic mapping of a smart city in formation, and the role of political and administrative geographies and specialist smart city units in shaping that formation.
\end{abstract}

\section{Keywords}

Governance, procurement by challenge, Small Business Innovation Research, scaling, smart city, Smart Dublin, strategy, test-bedding

\section{Introduction}

A somewhat ambiguous term, 'smart city' is now at the vanguard of concepts concerning urban development, replacing and incorporating a series of precursors that included the wired city, innovation city, digital city, intelligent city and creative city (Hollands, 2008; Kitchin, 2014). The term denotes something inherently positive, for who can be for the 'dumb city'? It also suggests more than the embedding of digital technologies in urban infrastructures, hinting at the clever entwining and integration of systems used to govern cities, enabling the 'breaking down of silos', 'joined-up thinking' and 'data-driven, real-time control'. Importantly, the notion of a smart city is not confined to the operations of local government, with individuals gaining access to smart services, both public and private, through a plethora of smartphone apps created by industry or citizens.

\footnotetext{
Corresponding author:

Liam Heaphy, NIRSA, Maynooth University, Maynooth, County Kildare, W23 F2H6, Ireland.

Email: liam.heaphy@mu.ie
} 
While there is a relatively extensive literature concerning, on the one hand, the nature of smart cities in general and the roles of specific corporate actors (e.g. Hollands, 2008; McNeill, 2015; Söderström et al., 2014; Townsend, 2013) and, on the other, the development and deployment of specific smart city technologies (e.g. urban operating systems, control rooms, smart grids, smart parking, smart waste management, sensor networks, smart lighting), relatively few studies have examined the situated practices as to how the smart city as a whole unfolds in specific places (Kitchin, 2015). Initial studies include Ayona Datta's (2015) examination of the formation of Dholera City in India; Alan Wiig's (2016) study of Philadelphia's smart city initiatives; Michelle Cullen's (2016) examination of Portland, Oregon, and Dubuque, Iowa; Federico Cugurullo's (2016) research about the development of Masdar, UAE; and several studies on Songdo, South Korea (Carvalho, 2011; Kim, 2014; Shin et al., 2015; Shwayri, 2013). Interestingly, Dholera, Masdar and Songdo are all-new cities on greenfield sites. Moreover, both Wiig and Cullen's studies focus on the core role played by IBM in initiating smart city programmes. Studies focusing on the situated and contextual nature of smart city adoption in existing cities tend to focus on the roll-out of specific initiatives and technologies, rather than mapping out the panoply of smart city initiatives and how they work (or not) in concert.

In this paper, we map out at a city scale the various smart city initiatives underway, how they are managed and governed and how they are enrolled into a smart city framework. This analysis is important for four reasons. Firstly, it reveals the diverse initiatives that make up a smart city and the different configurations of information and communication technology (ICT) and regulations, policies, economic development strategies and governance and civic engagement practices. Secondly, it highlights how 'smart city interventions are always the outcomes of, and awkwardly integrated into, existing social and spatial constellations of urban governance and the built environment' (Shelton et al., 2015: 14). Despite the claims of multinational high-tech corporations that cities are a tabula rasa for innovation, smart city initiatives are layered onto or replace existing city systems and infrastructures, and fit within or rejig organisational structures and established modes of practice. Thirdly, it exposes how the development of a smart city is far from stable and linear in nature, but rather unfolds through a set of contingent and relational processes shaped by local governance practices, political priorities, political economic context and institutional settings. As such, the approach provides situated accounts of how smart cities emerge and are designed in practice. Fourthly, it illustrates the role of new institutional bodies within and across local governments in organising and promoting the smart city agenda. Many cities have created such bodies, but to date, the work of these units has been little documented.

Our empirical case is Dublin, Ireland, charting how Dublin has progressively framed and mobilised itself as a smart city by means of its 'Smart Dublin' programme during its formative phase over the course of 2015 and 2016. In particular, we are interested in how Dublin evolved from an 'accidental smart city', following Dourish (2016: 37), towards being an 'articulated smart city':

[T] he story of the accidentally smart city is not of one in which a single strategy and coherent design approach yields an urban space in which information is woven into the fabric. Instead, the city becomes smart ... [in a] piecemeal, gradual, disparate manner ... little by little, one piece at a time, under the control of different groups, without a master plan, and with a lot of patching, hacking, jury-rigging and settling.

While the development of a smart city will always remain somewhat 'accidental', unfolding through a diverse set of initiatives driven by varying actors and stakeholders pursuing different interests, in the 'articulated smart city' existing initiatives are corralled into the semblance of an overarching, coordinated, strategic and branded narrative, into which future smart city initiatives are likewise folded.

Our source material is drawn from an extended five-year research project, The Programmable City, involving 10 active researchers at any one time, and was generated in three ways. Firstly, a detailed audit and mapping of the smart city initiatives underway in Dublin in 2015 was conducted through desk research and querying key stakeholders. Secondly 
are three sets of interviews. The first set were 42 interviews with smart city stakeholders in Dublin conducted between February and May 2015 and designed to explore how they understood the concept of a smart city, the extent to which Dublin fulfilled those criteria and the challenges and solutions to Dublin evolving as a smart city. ${ }^{1}$ Interviewees were drawn from a range of sectors (eight from local authorities (LAs), nine from state agencies, six from large companies, three from small and mediumsized enterprises (SMEs), seven from universities, five from civic groups, three from lobby groups and one politician). The second set was 25 interviews focused on a selection of projects identified in the audit designed to understand their scope and nature and how they fitted into the landscape of city services conducted between October 2015 and April 2016. ${ }^{2}$ Projects selected were those already mainstreamed and used to deliver city services, and excluded pilot or terminated projects, or those deemed extremely narrow in scope. Interviews often also included a site visit to view the technologies in operation. Interviewees were drawn from a range of sectors ( 12 from LAs, four from state agency managers, five from industry, three from universities, one from a civil group). The third set reflects continued research focused more specifically on the establishment of a smart district in the Dublin Docklands and the forms of pre-commercial procurement (PCP) set up to support smart city challenges conducted between February 2016 and May 2017. ${ }^{3}$ Thirdly, our ethnographic fieldwork involved the facilitation of 'challenge' workshops in late 2015 and early 2016 that sought to identify key issues and 'challenges' relevant to each of the four LAs, with the general aim of tackling inefficiencies in service delivery and improving the lives of citizens. Participants divided into groups of five to seven, each having members with different responsibilities and competencies. There were two 40-minute sessions of intra-group discussion and debate moderated by a facilitator, structured around a standard classification of smart city technologies developed by Giffinger and Pichler-Milanović (2007) and adopted by the European Union (EU) and the Institute of Electrical and Electronics Engineers (IEEE). Subsequently, reports with feedback were prepared, followed by further stakeholder engagement to refine and prioritise challenges and develop associated problem statements. Furthermore, one of the authors has also been an external member of the Smart Dublin steering group.

The ethnographic fieldwork, while involving the researcher team in the process of making Dublin a smart city, provided an insider counterpoint to the first set of interviews, as well as providing access to the knowledge and internal politics of key actors working in the various departments of the four LAs, the Smart Dublin team, the steering committee and the advisory network. The researchers did not work for the LAs or Smart Dublin, nor did they drive the agenda or strategy, but rather helped facilitate exchanges with the aim of gaining insights and creating reflexivity among the actors involved. This reflexivity was circular, feeding back into our own understanding of smart urbanism, informed through observation and interchange (Czarniawska, 2007), often with personnel from a research background who had moved into the public sector or industry.

\section{The Dublin region and the 'accidental smart city'}

While the Greater Dublin Area extends into the counties of Meath, Kildare and Wicklow, the principle core urbanised area is administered by four LAs covering an area of $920.66 \mathrm{~km}^{2}$, with a population of 1,347,359 (Census, 2016). These include Dublin City Council (DCC) at its centre, Dún Laoghaire Rathdown and South Dublin County Councils to the south and west and Fingal County Council to the north. Each LA is independent and autonomous with its own chief executive, service departments and elected officials. There is no city-wide mayor or overarching governance body that coordinates and oversees the four LAs. The Dublin Regional Authority had limited powers and was dissolved in 2014 and its replacement, the Eastern and Midland Regional Assembly, overarches 12 LAs and similarly has no executive function with respect to the day-to-day operation of the four Dublin LAs. The mandate for each LA is restricted, covering planning, housing, waste, roads and traffic, parks and recreation and local enterprise, but not health, 
education, social services or public transit, which are delivered through other agencies. While the four Dublin LAs have open channels of communication, collaboration between them is rather limited, each focusing on the delivery of services within their respective areas.

This fragmented governance structure has meant that up until 2014, smart city initiatives have largely been pursued individually by each LA. Table 1 details 28 mainstreamed, operational smart city technologies used by the LAs to manage city services, classified using the Giffinger and Pichler-Milanović (2007) smart city typology. ${ }^{4}$ As the descriptions make clear, they are broad in scope and seek to address a diverse range of issues.

The technologies detailed in Table 1 are largely proprietary, were initiated at different times and use varying hardware, software, standards and data formats that can make them incompatible with other systems. The traffic control room, for instance, has undergone several iterations, with SCATS (Sydney Coordinated Adaptive Traffic System) installed in 1989 and continually evolving over the past two decades (McCann, 2014). Later projects, such as the community hackathons and open data portals, relate to prevalent global trends towards civic hacking and open knowledge sharing. The systems also work across different spatial scales - buildings, within LAs, across LAs, city-wide, nationally - due to institutional remits and multiple organisational practices. With respect to the national scale, in a relatively small European State (population 4.6 million) with no other city region comparable in size to Dublin within its borders, the national scale represents a more efficient investment for technologies such as pavement management systems, travel smartcards and real-time passenger information systems. In other cases, initiatives are fragmented not only across LAs, but also across departments within those authorities, with some staff unaware of other smart city technologies in their own organisation.

It was clear from our interviews that the systems detailed in Table 1 were independently conceived and operated, procured or built to perform a particular task outside of any wider smart city strategy. Moreover, the four LAs, and the city more broadly, have acquired digital capacities slowly and accumulatively, with the various elements not designed to be part of a wider whole. Such accretion produces a certain path dependency and legacy systems that are not straightforward to append or replace. The consequence of this fragmentation and diversity was that up to 2015, Dublin, while deploying several smart city technologies, many of which had an important role in the management of the city (such as the traffic control system and Leapcard), was not widely thought of as a smart city within Dublin or elsewhere. This was made clear in our first set of interviews where stakeholders were universal in their view that Dublin was not a smart city leader:

Well, I suppose I can think of plenty of cities that have done less and I can think of plenty of cities that have done more. I don't think I would say we are in the upper third to be honest ... I think there aren't that many things you could say on the streets of Dublin that you'd be credible saying, 'we are a leader in smart cities'. (DSC24, director, state agency)

I wouldn't say Dublin is a smart city at all. I would say it wants to be perceived as a smart city and it is keen to be an early follower but it is not a leader in any way, shape, or form. (DSC09, owner, community development startup)

Interviewees also noted that the smart city landscape was highly fragmented:

I don't know where the problem is: is it that everything is fragmented, that there are different city councils, different authorities that have to be consulted and different boards? If you look, you have DCC, you have Fingal, Dún Laoghaire Rathdown, you have got all of these different councils, are they all trying to do different things or are they all in agreement or what happens? My personal feeling is that it is a little bit fragmented, what goes on in the city. (SD25, project coordinator, university)

Collectively, interviewees identified a wide range of issues that they felt held Dublin back from becoming a smart city, including:

- a piecemeal approach and a lack of a guiding strategy with associated mission and goals;

- an absence of joined-up thinking across LAs, their departments and other stakeholders, and a preponderance of siloed systems; 


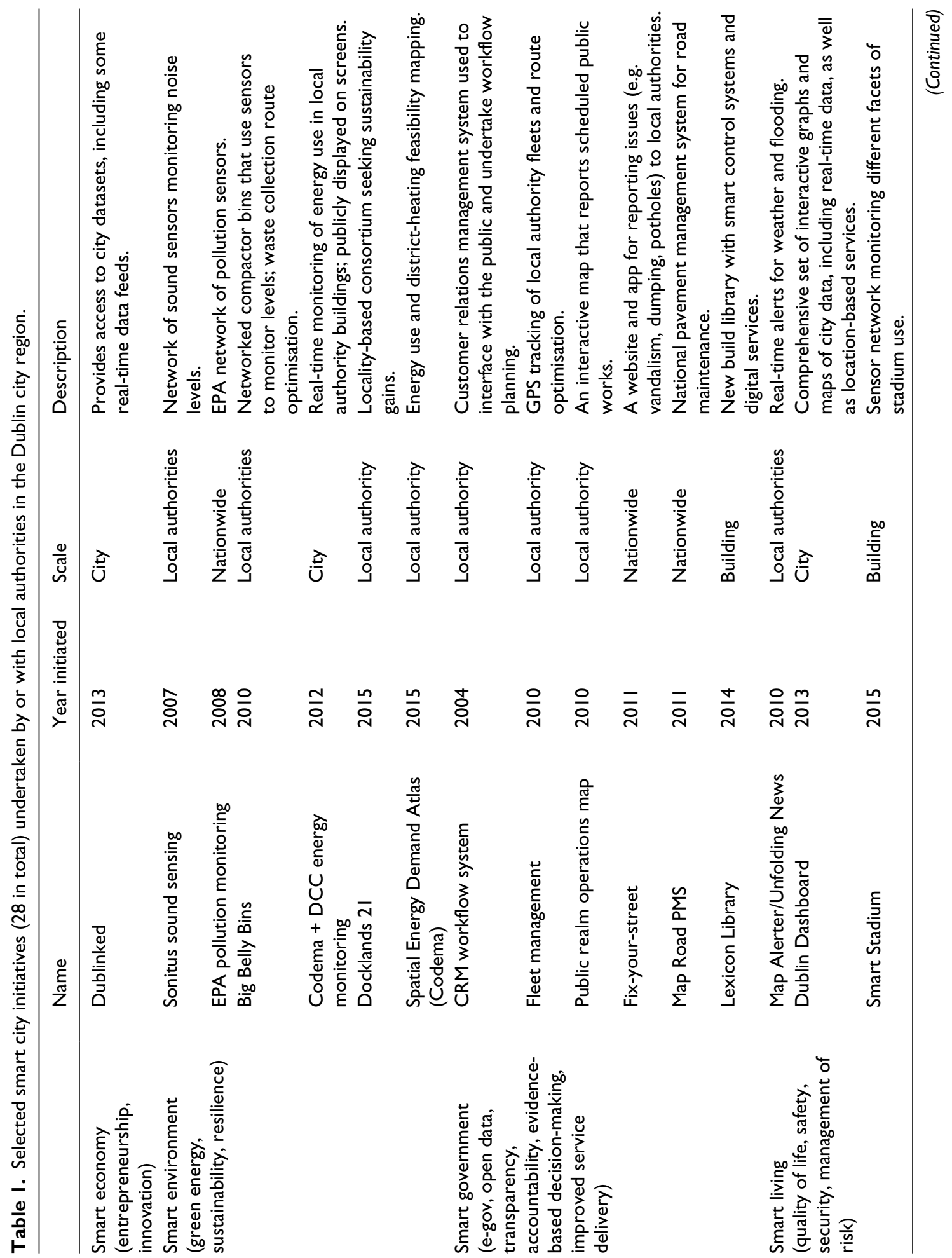




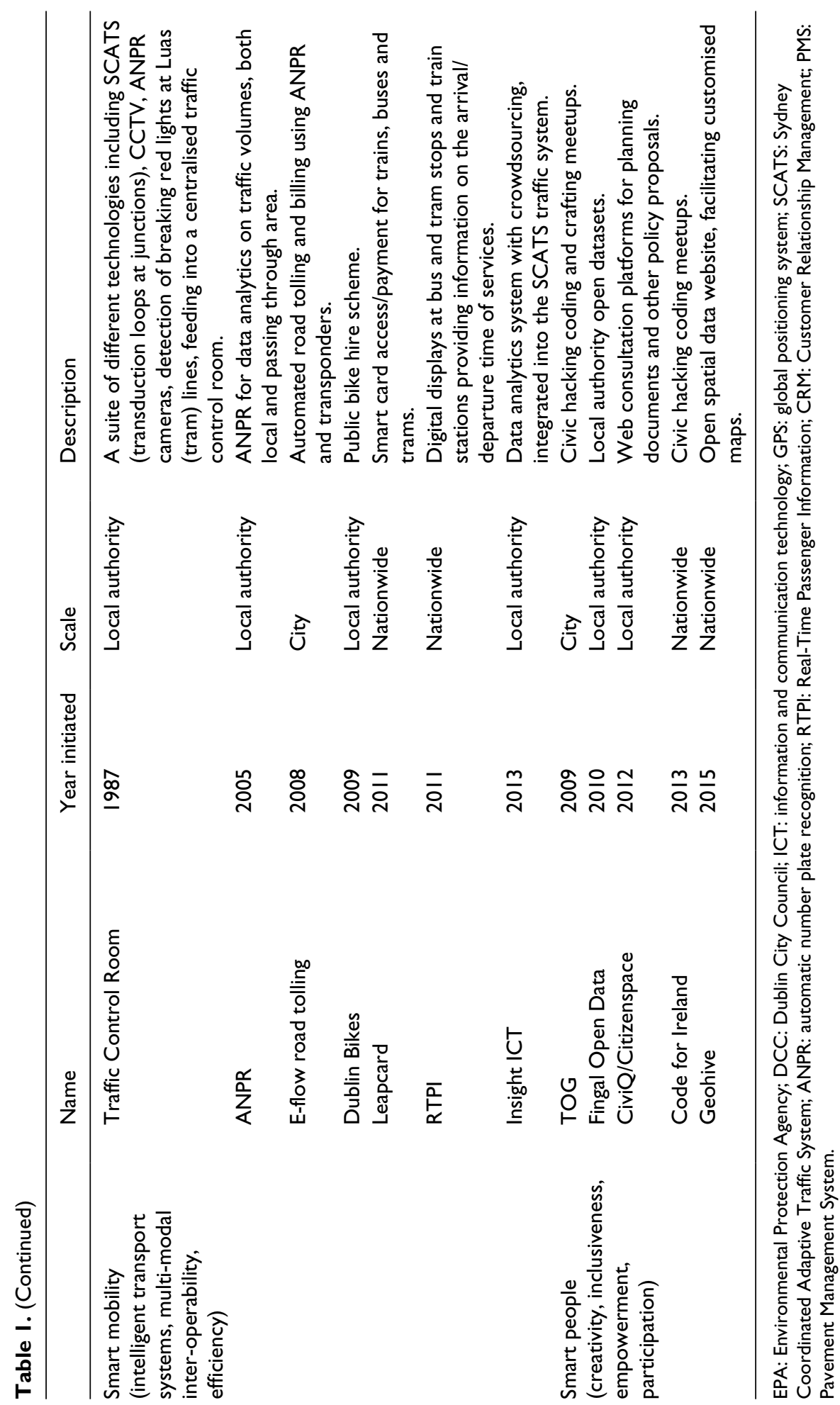


- weak governance structures and an absence of directed leadership;

- a lack of a formalised process of engagement between LAs, stakeholders and others;

- under-resourcing of investment and weak staffing and skills capacity;

- an imbalance in the capacity and enthusiasm for LAs and a lack of cooperation between LAs to create sufficient economies of scale;

- inflexibility in the working practices and a staid cultural mindset in LAs with respect to procurement, experimentation and operations; and

- too many political or regulatory barriers for implementation.

Nonetheless, most interviewees also felt that the city was progressing and, moreover, that there were great opportunities to be gained from pursuing a smart city agenda.

I don't think there is a city that is unbelievably advanced in this game, I think it is a real emerging space. That is why I think it is such a big opportunity for the city to really grab this by the neck and go for it. With the right leadership, the right governance, and the right partners the opportunity is huge. ... We seem to be moving faster than I thought we would and I think there are exciting initiatives and projects that are emerging or are under way. (DSC01, LA worker)

Aware of the perception that the city region was not a smart city leader and that there were potential opportunities to become a recognised smart city, the four LAs took the collective decision in 2015 to create a smart city unit and articulate a new vision for Dublin as a smart city branded as 'Smart Dublin'. In so doing, it sought to start a shift from Dublin as an 'accidental' to 'articulated' smart city.

\section{Smart Dublin and the articulation of the smart city}

Smart Dublin (2018) has as its stated aim, 'to engage with smart technology providers, researchers and citizens to solve challenges and improve city life' and builds on several previous initiatives. This includes Dublinked, established as an open data repository by the four Dublin LAs and Maynooth University in 2011. Dublinked was the outcome of, firstly, a recommendation by the Creative Dublin Alliance to the Dublin Regional Authority's 2009 economic strategy and, secondly, of having attracted IBM's global smart city research team to Dublin in exchange for access to city data. Rather than being grounded in discourses of accountability and transparency, Dublinked was envisaged as an economic innovation initiative designed to stimulate and fuel an open data economy. Also of importance was the DCC strategy initiative 'Digital Dublin' (2013), which organised the Dublin Digital Leadership Forum and drafted a Digital Dublin Masterplan to 'develop Dublin as one of the world's leading smart, innovative and intelligent cities'. Dublinked was the logical foundation structure for Smart Dublin when the latter emerged in 2015, given its existing institutional structure, governance and funding arrangements. Smart Dublin was formally launched in March 2016, and although a city region body, is housed in DCC and presently consists of four core staff members. ${ }^{5}$ Its organisational structure is set out in Figure 1. The steering committee consists of two members of staff from each LA, one being more technical and the other typically service or enterprise focused, plus a representative of Maynooth University, and it is chaired by one of the LA CEOs. It has appointed an advisory network, comprising 40 stakeholders representing industry, government, civil society and academia, which has met twice prior to time of writing (March 2018).

The primary objectives of Smart Dublin are to increase the visibility of existing smart city-related initiatives in the city region and stimulate new partnerships and city services. Its remit covers promoting data-driven networked infrastructure and fostering economic growth and entrepreneurship, producing more efficient city services, improving transportation flows, tackling flooding and other environmental concerns, attracting inward investment and encouraging indigenous start-ups and SMEs, and opening data and encouraging civic engagement. It seeks to do this in the context of a limited role for the public sector in urban transformation due to the deep recession in Ireland linked to 


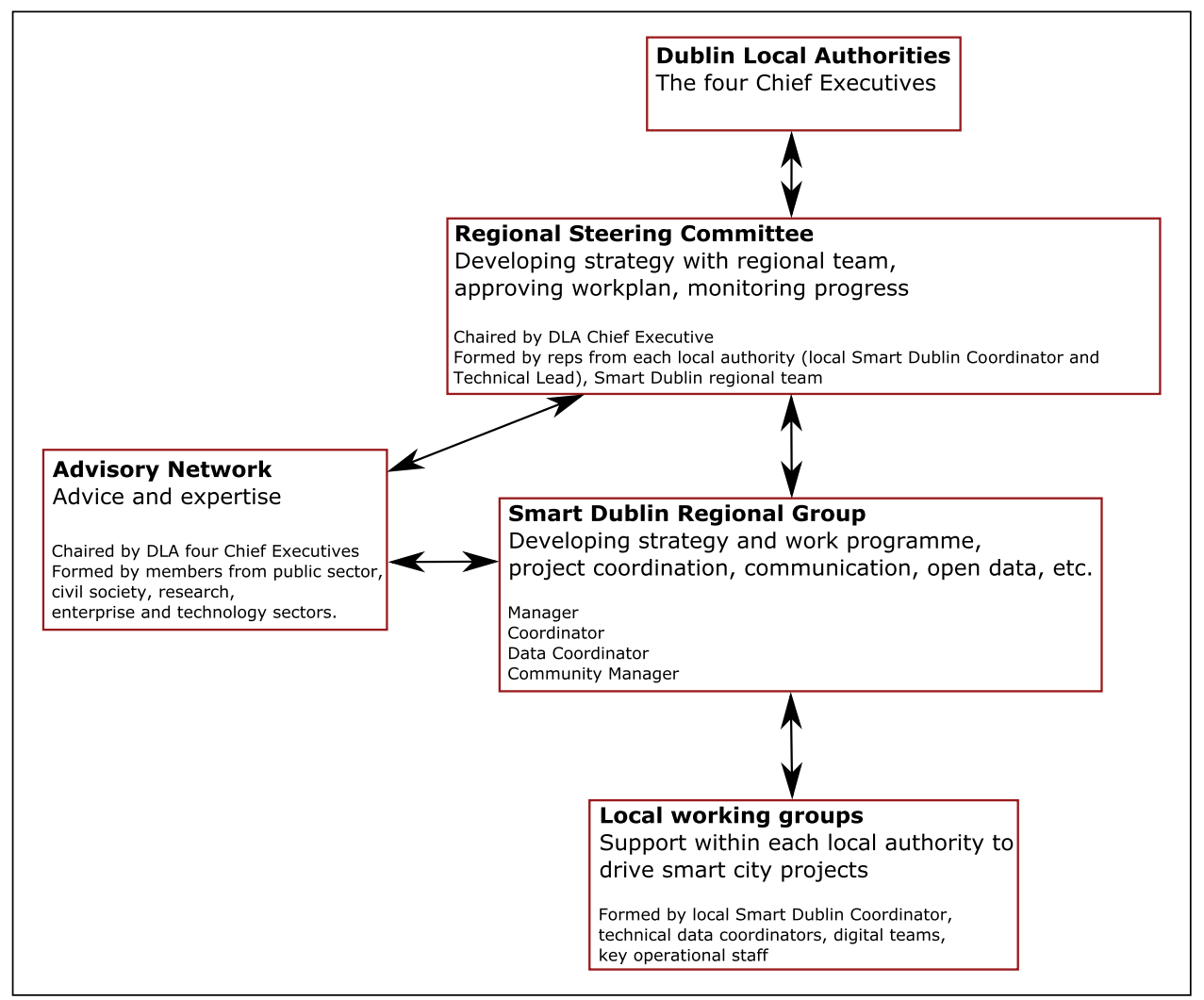

Figure I. The organisational structure of Smart Dublin.

the 2008 financial crash, related austerity measures and the commensurate need to reduce the costs of public services. As a governmental unit, Smart Dublin provides a central hub for managing relations with companies and university research institutes wishing to partner with the four LAs on smart city initiatives, leveraging on the high-tech ecosystem formed by multinationals, SMEs and start-ups settled in Ireland.

Part of the narrative supporting the work of Smart Dublin is that LAs are behind the technology curve with respect to state-of-the-art ideas and systems for managing cities. They lack the core skills, knowledges, resources and capacities to address pressing urban issues and maintain critical services and infrastructures, which are becoming more socially and technically complex and require multi-tiered specialist interventions. As one startup entrepreneur stated:
I think the problem ... is that the people who are leading it just don't know enough about what they should be doing. (DSC42)

Moreover, their procurement processes and regulations are outmoded and actively block progress.

The city managers said, yes just make it happen. But as soon as we tried to make it happen, that was when all the barriers started to present themselves ... So it is actually very hard for a company ... to say, here is something for you to go and try. 'Oh no, we can't do that - public procurement, stakeholders, territories, patches, and all that kind of stuff.' I would actually fear that if someone presented a cure for cancer ... we wouldn't be able to accept it. (DSC07, director, university incubator)

Instead, they need to draw on the competencies held within industry that possess sufficient expertise to guide city administrators and deliver better city 
services through public-private partnerships, leasing, deregulation and market competition, or outright privatisation (Kitchin et al., 2017; Shelton et al., 2015). In particular, they should collaborate with the plethora of international ICT companies based in the city:

So, the fact that you have all these technology companies in here, you are not actually utilising that to the benefit of the city; so, you are not making the most of the opportunity that you now have, I think. (DSC34, director, state agency)

Within this mindset, the place of the public sector is to challenge companies to offer solutions to a set of problems, and foster innovation and entrepreneurship with an open data policy and new ways of tendering. As such, Smart Dublin acts as the bridge between external expertise and the city administration, building new partnerships to keep abreast of the technology curve and create efficiencies in public service delivery.

Smart Dublin has pursued four tactics designed to foster 'smartness', marking a significant change in how Dublin tackles urban issues and innovation. Firstly, it has sought to prepare a smart city strategy and create a formalised approach to engagement with stakeholders. Prior to the formation of Smart Dublin there was a sense that companies and universities were formulating initiatives, while the city administrations were merely reactive. Moreover, there was no formalised process of engagement between stakeholders, with some having better access to decision-making networks than others, and decisions being made on an ad hoc basis.

I think it would be extremely difficult ... to get into DCC.... I personally have had dealings with the council and I personally have contacts in there and I know, not necessarily who I have to talk to, but I know who I have to ask to be told who I have to talk to, and most people in Dublin don't have that privilege. So, if you are not somebody who has had any interactions with them it is a very, very difficult place to put down any sort of a foothold. (DSC13, leader, civic organisation)

If you were IBM or Intel you can kind of walk through the front door but anybody else, they don't know the route or the procedure or... (DSC23, LA worker)
The result was a set of arbitrary projects that suited some stakeholders but poorly served the city. In response, Smart Dublin now provides the four LAs with a single point of contact - a 'front door' through which everyone enters - and a framework for evaluating each smart city proposal in an equal and transparent manner.

Secondly, Smart Dublin has embraced test-bedding as a means of urban development. Test-bedding is often synonymous with urban 'living-labs' and describes 'a controlled and often isolated development environment in which to test the operability of new technologies, processes, or theories for large systems' (Halpern et al., 2013: 290-291). Urban space becomes a distributed laboratory for testing smart city technologies, especially those utilising Internet of Things (IoT), run by public and private stakeholders to help solve city challenges and attract investment. Current test-beds include Croke Park as a Smart Stadium (an 80,000-seater venue), where a consortium of companies and universities are trialling sensor and camera technologies for managing the stadium infrastructure, the pitch, concession stalls and crowds, and the experience of events (Panchanathan et al., 2016), and the newly designated 'smart docklands', an area for trialling new smart city technologies, such as sensor networks, smart lighting, smart parking and smart grids (Heaphy and Pétercsák, 2018). The latter is within the Dublin Docklands, an area that is home to high-tech firms including the European headquarters of Google, Facebook and LinkedIn, as well as numerous start-ups and incubator spaces such as Dogpatch Labs. Test-bed urbanism is an opportunity to scale from the bench and lab to the street and urban environments, and to collaborate with other likeminded operations, including start-ups, SMEs and multinationals:

Dublin is a nice small community to work in, to start on a scale and then, when we have something right, we can take it somewhere else. We will start a trial soon in New York City and that has the potential to be much, much bigger. But we have the understanding of what it takes from having a nice local small scale here, and we have a very clear picture so that when we go to talk to somebody new they can see that we understand the problems or understand what is needed. (SD20, start-up entrepreneur) 
The indefinite goals and progressive re-adaptation makes test-bedding consistent with the futureoriented nature of PCP, particularly in the form of 'procurement by challenge' and Small Business Innovation Research (SBIR), which is the third tactic Smart Dublin is adopting. PCP has been recently adopted by the EU to foster ideas where a substantial amount of research and development is still needed to obtain a final product or service. The process does not presuppose the optimal solution to a problem for which tenders are then sought, but rather seeks to develop a range of solutions from which one will be selected. SBIR operates under EU PCP rules and is a pan-government, structured process, enabling the public sector to engage with companies, especially start-ups operating in the high-tech sector. To fund PCP, Smart Dublin has successfully applied for SBIR funds from Enterprise Ireland (the state agency responsible for developing and supporting indigenous companies). To date, four 'challenges' have been completed on increasing cycling take-up in Dublin, illegal dumping of waste, flood management, and assisted wayfinding.

Lastly, Smart Dublin is seeking to leverage a scalar shift from individual LAs to the Dublin city region scale as a joint endeavour. This scaling helps to bridge the fragmenting of governance and administration across the city and facilitates the sharing of knowledge between actors. While most attention is usually directed at DCC, which covers the city centre, Smart Dublin informs stakeholders of opportunities with the other LAs and can provide introductions and broker between companies, universities and the LAs. A scalar shift also potentially creates economies of scale for financing and implementing smart city technologies that work optimally at the city scale, rather than in localised areas. A further scalar transformation is the All-Ireland Smart City Forum (launched 9 December 2016) that includes all the major cities of Ireland and Northern Ireland in order to share best practices and coordinate projects and tenders.

It is important to note that Smart Dublin has no control over the many smart city initiatives across the city region. Rather, its role is one of articulation (creating a smart city narrative and strategy), initiation (introducing and seeding new potential projects, partnerships and systems into the four LAs) and promotion (selling the idea that Dublin is a smart city and is open for smart city initiatives and businesses). While addressing some of the aforementioned barriers that were creating fragmentation, it also creates, promotes and maintains a discourse where private and civic initiatives in the Dublin region can coalesce, thereby putting Dublin 'on the map' of global smart cities.

\section{From 'accidental' to 'articulated' smart city?}

Smart Dublin has a small team and limited resources. Nonetheless, it has begun to shift Dublin from being an 'accidental' smart city to an articulated one; that is, from a situation of various disconnected and uncoordinated smart city initiatives to one framed by a narrative in which Dublin is 'open, engaged, connected', and there is a unit whose role it is to envisage and help realise Dublin as a smart city. There is evidence to suggest that the activities being rolled out are having the effect of transforming its profile to one of a smart city, both locally and internationally. The Smart Dublin challenges have attracted relatively large numbers of expressions of interest and submissions by local start-ups and SMEs and have been widely covered in the national media. In conjunction with three research centres and industry partners, Smart Dublin is a participant in a new Science Foundation Ireland $€ 14.5 \mathrm{~m}$ research programme, ENABLE. In addition, the city was shortlisted as a finalist in 2017 as 'Smart City of the Year' at the Smart City World Expo and Congress in Barcelona, is a participant in European consortia, such as the URBACT project SmartIMPACT with a focus on the docklands area, and is now regularly asked to participate in Horizon 2020 (H2020) and lighthouse city initiatives. However, that profile has taken a particular form that aligns strongly with the neoliberal approach to urban governance, planning and economic development that has operated since the late 1980s (MacLaran and Kelly, 2014; MooreCherry and Vinci, 2012). So, rather than Smart Dublin being 'open as in open data', 'engaged as in engaged citizens' and 'connected as in a connected city', it is 'open as in open ended or open market', 'engaged as in otherwise engaged' and 'connected as in loosely coupled'. 
Test-bedding and procurement by challenge are explicitly open-ended, ad hoc processes, seeking to foster innovation and creativity, and to conceive, build and test new urban solutions iteratively. Smart Dublin is actively pursuing 'experimental urbanism' (Evans et al., 2016) as an economic growth and urban development strategy, offering companies access to city services, infrastructures and personnel in a form very different to the usual relationship between companies and city administrations. While the process of testing and trialling is meant to be leading to fully implemented and mainstreamed systems, investments in experimental urbanism runs the risk that parts of the city become eternal 'beta versions'. Of course, cities are always in the process of becoming, unfolding in time and space as a diverse set of processes that shape city life and urban development. However, city administrations usually seek stability and certainty, updating systems as and when needed, rather than encouraging continual flux and first-mover risks in adopting urban technology. With respect to the latter, urban spaces and city management are further repositioned as open markets in which companies can co-create and work with the State, deepening and further legitimising the marketisation and public-private provision/privatisation of city services and infrastructure. This raises the following questions. For whom is the smart city being developed? What is the role of the State in urban development? How does the smart city unfold in practice through public and private means?

In the case of Smart Dublin these normative questions have little been considered or debated beyond formulating broad mission statements and goals, with attention focusing on the more instrumental concerns of improving city services and economic growth. This reflects, in part, the originating context of Smart Dublin in the economic crisis, austerity and recession, and a corresponding mandate for driving innovation and job creation. Public sector stagnation in the wake of large cutbacks and a hiring freeze, the emphasis on marketbased solutions, and the rollout of funding streams such as SBIRs and domestic and EU academia-industrypublic sector grants have meant that it has been easier to engage with the private sector and to drive initiatives that focus on supporting a growth-based, indigenous, innovation infrastructure, such as PCP and state-backed start-up incubators/accelerators.
The focus on innovation and economic development has meant that citizens are only the 'most important component' in the sense that ultimately they will be the beneficiaries of the smart city, more informed and receiving better services, but not acting as participants, co-creators or decision-makers:

[T]he key stakeholder at the end of the day is a more informed citizen and a citizen that can interact and engage with their city in a better way. And I think that is about awareness building, it is about us being very upfront and clear in terms of why we are doing this and I think there's better opportunities for us in terms of that engagement than we have been developing up until now. (DSC01, LA worker)

It is the commoning of data through Dublinked that connects a central core of IoT and data analytics to a broader citizenry.

I think for me a core component of a smart city is an open mass democratic city so that information is open to citizens and is usable by citizens and probably that it is not just about public data. So a really smart city, if it is a city about being a data enabling city, then it has to be not just public data but also private data, and by that I mean it has to be not just private individuals but business. So I think a lot of the stuff we see in smart cities at the moment is about enclosure of public data and an attempt to take it out of the public realm and convert it into some kind of private, monetary or some financial value on the back of it for private gain. And I think any component of a smart city has to have the reverse as well. Private information is used to feed the digital commons. (DSC09, owner, community development startup)

Smart Dublin began community engagement exercises in 2018 at a local scale in relation to the 'Smart Docklands' test-bed. It is taking place after the key structures of Smart Dublin and its challenges have been put into place and is very limited or absent in other initiatives. Smart Dublin has largely defaulted to operating a form of civic paternalism and stewardship, deciding on what is best for citizens in consultation with staff from LAs and acting on their behalf, rather than creating a more citizen-centric vision of a smart city (Cardullo and Kitchin, 2019).

One issue that is significantly shaping the formation and geography of new smart city initiatives in the city is a large imbalance in the enthusiasm, 
commitment and resourcing by the four LAs. This reflects the political geography of the Dublin city region, which has no corresponding scale of governance. Beyond the four Dublin LAs is the national scale, to which technologies such as real-time passenger information and the Leapcard have been extended by the National Transport Authority, and a road management system, Map Road PMS, coordinated by the Local Government Management Agency (see Table 1).

I think the other thing that is happening is Dublin calls itself a smart city but it's a smart city within the canals, again I wear all my former hats, it has to be a city in region, if you want to be smart it has to be a city in region and that goes back to how are you planning for that? You go to Copenhagen, they don't look within the city centre of Copenhagen, they plan into all their hinterlands, into all their towns that dot Copenhagen and they have a strong planning ethos that they don't move away from. (DSC09, owner, community development startup)

Furthermore, within the limitations of the political status quo, DCC has by far the most number of staff interested in and actively applying the smart city approach, and the greatest number of projects and connections with companies. They were the initiators of test-bed urbanism and pre-commercial forms of procurement within the city and are the largest and wealthiest LA, given the business rates generated by the city centre location. Consequently, Smart Dublin is dominated by DCC and the organisation occasionally suffers from the associated politics and disharmony that go with this imbalance. Several interviewees talked of this fragmentation and imbalance and the need for a Mayor across all four LAs with real powers and a leadership role.

I would love if we had a Mayor ... I think the big problem for us as a city is the limited range of services that we have responsibility for and I think it seems that the cities that are really leading in this space have much more control of the policing, health, social services, education and all the different city services, waste and water management, all that kind of stuff. I think that seems to be the first bit, good governance, strong leadership, so if we could import that I think we would be onto a good starting point. (DSC07, director of a university incubator)
A debate on the need for a new metropolitan city region authority extending to the functional urban area, including the commuter belt, was not in great evidence, beyond discussion on coordination and empowerment of the LAs themselves and the interviewee quoted above. Consequently, Dublin's 'accidentalness' remains in the form of many largely disconnected and uncoordinated smart city initiatives, as Smart Dublin does not have the power or capacity to pressure other departments into channelling their initiatives through the organisation. Nevertheless, they play a modest role among a wider constellation of actors that are successfully drawing in further funds for innovation research. Remaining are all the same planning challenges that predate the economic crisis, including housing shortages, urban sprawl and the excoriation of urban centres in favour of car-based retail outlets (Moore, 2007). In the City Development Plan (2016-2022) for DCC, Smart Dublin has a supportive role for two DCC policies for delivering ICT infrastructure (SI29 and SI30), as well as for the two objectives of coordinating telco infrastructure and supporting 'the emerging Smart Dublin Framework which will allow greater flexibility for the city to work with universities, entrepreneurs and companies, to co-innovate, test and deploy new urban solutions' (Dublin City Council, 2016: 158). The actual projects related to test-beds and procurement in the city are not explicitly mentioned in development plans, and Smart Dublin sits outside national statutory strategies, such as the new National Planning Framework. Nevertheless, Smart Dublin does liaise with planning and communities at the local scale where, most clearly in the case of the Dublin Docklands, Smart Dublin has the capacity to assemble large and durable partnerships between many disparate actors, including planning, transport and communities, rather than solely with the private sector.

It's not so much saying how they can create a smart city. It is how can they enable the smart city? I come back to the word enable because smart cities will only happen through partnerships and collaboration, and the right partnerships and collaboration, and the local authorities' role is not to make all of those happen but is to enable, enable through the functions that they have. (SDD06, sustainability consultant) 
This enabling function is becoming clearer as the original constellation of actors that initiated the innovation-based growth strategy for Dublin acquires funding and support for localised interventions in urban test-beds and selected projects within the denser urban core.

Dublin is thus set to continue being an accidental smart city, albeit one whose accidental nature is veiled by the branding work of Smart Dublin, giving the impression that Dublin is more unified and coherent in its approach than it actually is, which in turn serves place-branding and marketing, aids the capture of foreign direct investment of smart city enterprises, gains political capital and secures funds for the initiatives to which it does contribute. In this sense, Smart Dublin can be considered a success, although the development of an open data portal, an alliance of stakeholders and the creation of a smart district hardly make for an open, connected and engaged smart city at scale. Its success is evident in subsequent research on the Smart Docklands test-bed, where Smart Dublin has been the vehicle for a broad advocacy coalition of corporates, local government and the start-up community to mobilise resources to support innovation in Ireland and access European funding (Heaphy and Pétercsák, 2018). Participants from the local ICT sector, home to the European headquarters of many global firms with an increasing investment in research and development, were generally positive towards the 'open, engaged, connected' approach of Smart Dublin with whose staff many have working relationships.

The present situation is unlikely to change in the short-term, given the political and administrative geography and the lack of power afforded to Smart Dublin to actively break down silos, coordinate resourcing and formulate strategy across departments and LAs. Such agency would only be achieved if there was a single political office directing city services and coordinating policies with the aims and ethos of Smart Dublin placed at its heart. Such a political geography is only realised through a unitary city authority, which is why such cities (Barcelona, Amsterdam, Vienna and Singapore were frequently cited as such in our fieldwork) are often considered archetypal smart cities.

\section{Conclusion}

As premised by Dourish (2016), our mapping of smart city initiatives in Dublin reveals that they were deployed in an ad hoc, piecemeal, uncoordinated manner. There was no smart city master plan. In fact, there was very little coordination or even awareness of initiatives across departments within or between LAs. Smart Dublin has sought, in part, to address this accidental nature and to create a more articulated and coordinated smart city landscape. However, while Smart Dublin has been somewhat successful in creating a smart city narrative and branding Dublin as a smart city, it has taken a very particular path in this process, focusing strongly on economic and urban development. To a large degree, Smart Dublin operates as an economic support unit, forming partnerships with companies and universities to facilitate urban testbedding and attract inward investment through experimental funding schemes. It has not yet addressed the existing accidental and uncoordinated nature of Dublin as a smart city and in many ways actively contributes to that accidental nature through proliferating smart city projects through test-bedding and PCP, which are largely uncoordinated and non-interoperable beyond a shared, overarching narrative. Moreover, despite recent limited citizen engagement, Smart Dublin and the city's smart city initiatives are citizen-focused only to the extent that citizens are envisioned as users and beneficiaries of better services and open data (Cardullo and Kitchin, 2019) and have largely been introduced by city technocrats rather than through a politically mandated process. Such an approach should perhaps not be a surprise given the wellembedded and documented neoliberal ethos in the city that favours the marketisation and privatisation of services and generous state supports for private enterprise (MacLaran and Kelly, 2014) and the fractured political and administrative geography of the city. The accidental smart city then continues to be produced despite attempts to create a more articulated vision. Indeed, the various fragmented 'little pockets of innovation', such as urban test-beds and challenges, would seem to prosper within Smart Dublin because masterplans are absent and processes open-ended. In this sense, Smart Dublin may 
represent a comfortable and loose ground for economic development, but only in terms of smallscale atomised innovation.

Our contribution to understanding the smart city more generally is threefold. Firstly, we have demonstrated the importance of mapping the whole smart city landscape within an urban domain rather than focusing on particular initiatives or enterprises (McNeill, 2015; Söderström et al., 2014). Such a mapping reveals that smart city initiatives are largely conceived and built in a gradual, piecemeal manner by different parties, and are deployed under the control of multiple actors. As yet, few cities (e.g. Barcelona, Vienna, Montréal) internationally have developed smart city strategies or masterplans (especially small to medium-sized cities), and despite the projected hopes of urban operating systems, integrated control rooms and smart city standards initiatives, the smart city will largely continue, we believe, to be accidental rather than by design. No doubt, integrating solutions, standards and strategies will produce a degree of coordination and interoperability, but they will not be able to tame and corral all the stakeholders, actors and technologies at play in the city into a unified whole. As such, the articulated smart city will always remain to some degree accidental, despite the hopes and ambitions of advocates and developers (Kitchin et al., 2017).

Secondly, we have demonstrated the role of political and administrative geography in the development of smart cities, an issue that has so far been largely ignored in the smart cities literature other than to note the need for coordination and joined-up thinking across departments, agencies and municipalities (Batty et al., 2012) and a few studies that have examined modes of governmentality enacted through smart city technologies (Klauser et al., 2014; Luque-Ayala and Marvin, 2016; Sadowski and Pasquale, 2015; Vanolo, 2014). A city's administrative geography can have a profound effect on the deployment of smart city technologies that need to work at scale, such as transport solutions like smartcards, smart parking and bike-sharing, that need to cover entire functional territories. There can be marked differences in the smart city services that citizens can access in different jurisdictions due to resourcing constraints and prioritisation. Such a situation exists in Dublin, where the fragmented nature of Dublin's local government into four autonomous jurisdictions is contributing to the piecemeal, uneven and accidental nature of smart city policies and initiatives. The partial solution to this fractious governance has been the formation of a unit that cuts across all four LAs, with a shared budget and staff. However, while the unit is shared between the LAs, it has no executive powers of coordination, only able to lobby LA departments to embrace the ideas and ideals of smart cities and use Smart Dublin to promote Dublin as a smart city. It thus has limited scope to address many of the key criticisms of our interviewees, such as lack of leadership, weak governance and insufficient economies of scale, and in many ways its existence is largely symbolic.

Thirdly, we have documented the process by which an accidental smart city starts to become an articulated one in relation to dedicated smart city units, not simply through the creation of a discourse, but also through material programmes of work. Smart Dublin's role is explicitly to produce a smart city strategy and narrative, to liaise and work with companies, universities and other LA departments and public sector agencies and to seek new solutions for issues facing LAs and citizens; it is to create an articulated smart city. It is highly active in this regard, acting as a key node in the advocacy coalition for smart cities (Kitchin et al., 2017) operating in the city, and liaising and working with international partners. Given limited resources and a wider context of a government prioritising job creation and the needs of companies, Smart Dublin is pursuing an articulated smart city through an economic development agenda that reflects the wider neoliberal ethos of government in Ireland and is attentive to the need to rejuvenate the economy in the wake of a recession.

Building on Datta (2015), Kitchin (2015) and Shelton et al. (2015), it is clear from our analysis that to fully understand the roll-out of smart city initiatives around the world there is a need for two complementary sets of studies that supplement the raft of studies focusing on the roll-out of specific technologies or initiatives in given locations. Firstly, there needs to be empirical case studies of the evolving smart city landscape across entire city regions, the interrelationships between smart city initiatives, the role of political and administrative geographies in shaping the development of the actually existing 
smart city, and the formation and activities of smart city units. Secondly, there needs to be a set of comparative studies examining how the smart city landscape is taking shape in different cities around the world, making sense of general patterns and localised contingencies (see Karvonen et al., in press). The analyses conducted to date indicate clearly that the creation of smart cities has taken different paths and forms across the globe, with commonalities around the knowledge economy and its supporting infrastructure (Angelidou, 2017; Calzada, 2017; Ersoy, 2017). Dublin largely concurs with its emphasis on the knowledge economy and the advancement of networked digital technologies and sensor arrays, yet the literature also notes alternative paths, such as the post-2015 anti-corporate position of Barcelona's new administration and their notion of technological sovereignty (Galdon, 2017) and the social urbanism and spatial justice approach of Medellín, Colombia (McLaren and Agyeman, 2015). Little is known at present as to the specificities of these differences and their effects, and yet smart city technologies are still being developed and marketed as universal solutions to urban issues.

\section{Declaration of Conflicting Interests}

The author(s) declared no potential conflicts of interest with respect to the research, authorship, and/or publication of this article.

\section{Funding}

The author(s) disclosed receipt of the following financial support for the research, authorship, and/or publication of this article: This work was supported by an ERC Advanced Investigator award (ERC-2012-AdG-323636-SOFTCITY).

\section{Notes}

1. Labelled DSCxx in subsequently quoted interviews.

2. Labelled SDxx in subsequently quoted interviews.

3. Labelled SDDxx in subsequently quoted interviews on the Dublin Docklands smart district, which were conducted in collaboration with Réka Pétercsák in Maynooth University.

4. We identified over 50 different smart city initiatives, but many were institutional or support-orientated (e.g. accelerator programmes for tech start-ups working on smart city solutions) rather than technical systems, or otherwise pilot or research initiatives.
5. Smart Dublin Regional Manager, Smart Dublin Regional Coordinator, Smart Dublin Technical Lead/ Data Lead and Smart Dublin Community Manager.

\section{References}

Angelidou M (2017) The role of smart city characteristics in the plans of fifteen cities. Journal of Urban Technology 24(4): 3-28.

Batty M, Axhausen KW, Giannotti F, Pozdnoukhov A, Bazzani A, Wachowicz M, Ouzounis G and Portugali Y (2012) Smart cities of the future. The European Physical Journal Special Topics 214(1): 481-518.

Calzada I (2017) The techno-politics of data and smart devolution in city-regions: comparing Glasgow, Bristol, Barcelona, and Bilbao. Systems 5(1): 1-18.

Cardullo P and Kitchin R (2019) Being a 'citizen' in the smart city: up and down the scaffold of smart citizen participation in Dublin, Ireland. GeoJournal 84(1): 1-13. DOI: 10.1007/s10708-018-9845-8.

Carvalho L (2011) Urban competitiveness, U-city strategies and the development of technological niches in Songdo, South Korea. In: Melih B (ed.) City Competitiveness and Improving Urban Subsystems: Technologies and Applications. IGI Global, pp. 197216. Hershey, PA: IGI Global.

Cugurullo F (2016) Urban eco-modernisation and the policy context of new eco-city projects: where Masdar City fails and why. Urban Studies 53(11): 2417-2433.

Cullen M (2016) Cities on the path to 'smart': information technology provider interactions with urban governance through smart city projects in Dubuque, Iowa and Portland, Oregon. PhD Thesis, The London School of Economics and Political Science (LSE). Available at: http://etheses.lse.ac.uk/3392/ (accessed 7 June 2017).

Czarniawska B (2007) Shadowing and Other Techniques for Doing Fieldwork in Modern Societies. Malmö: Liber.

Datta A (2015) New urban utopias of postcolonial India: 'entrepreneurial urbanization' in Dholera smart city, Gujarat. Dialogues in Human Geography 5(1): 3-22.

Digital Dublin (2013) A digital masterplan for Dublin. Available at: https://digitaldublin.wordpress.com/masterplan/ (accessed 5 February 2018).

Dourish P (2016) The Internet of urban things. In: Kitchin $\mathrm{R}$ and Perng S-Y (eds) Code and the City. London and New York: Routledge, Taylor \& Francis Group, pp. 27-46.

Dublin City Council (2016) Dublin city development plan 2016-22. Available at: http://dublincitydevelopmentplan.ie/ (accessed 5 March 2018) 
Ersoy A (2017) Smart cities as a mechanism towards a broader understanding of infrastructure interdependencies. Regional Studies, Regional Science 4(1): 26-31.

Evans J, Karvonen A and Raven R (2016) The Experimental City. London; New York: Routledge.

Galdon G (2017) Technological sovereignty? Democracy, data and governance in the digital era. Available at: http://lab.cccb.org/en/technological-sovereigntydemocracy-data-and-governance-in-the-digital-era/ (accessed 24 May 2018).

Giffinger R and Pichler-Milanović N (2007) Smart Cities: Ranking of European Medium-sized Cities. Vienna: Centre of Regional Science, Vienna University of Technology.

Halpern O, LeCavalier J, Calvillo N and Pietsch W (2013) Test-bed urbanism. Public Culture 25(2 70): 272-306.

Heaphy LJ and Pétercsák R (2018) Building smart city partnerships in the 'Silicon Docks'. In: Kitchin R, Coletta C, Evans L and Heaphy L (eds) Creating Smart Cities. London; New York: Routledge.

Hollands RG (2008) Will the real smart city please stand up? City 12(3): 303-320.

Karvonen A, Cugurullo F and Caprotti F (eds) (in press) The Smart City Compendium: Global Experiences in Urban Innovation. London; New York: Routledge.

Kim JI (2014) Making cities global: the new city development of Songdo, Yujiapu and Lingang. Planning Perspectives 29(3): 329-356.

Kitchin R (2014) The real-time city? Big data and smart urbanism. GeoJournal 79(1): 1-14.

Kitchin R (2015) Making sense of smart cities: addressing present shortcomings. Cambridge Journal of Regions, Economy and Society 8(1): 131-136.

Kitchin R, Coletta C, Evans L, Heaphy L and MacDonncha D (2017) Smart cities, epistemic communities, advocacy coalitions and the 'last mile' problem. it Information Technology 59(6): 275-284.

Klauser F, Paasche T and Söderström O (2014) Michel Foucault and the Smart City: power dynamics inherent in contemporary governing through code. Environment and Planning D: Society and Space 32(5): 869-885.

Luque-Ayala A and Marvin S (2016) The maintenance of urban circulation: an operational logic of infrastructural control. Environment and Planning D: Society and Space 34(2): 191-208.

McCann B (2014) A review of SCATS operation and deployment in Dublin. In: Proceedings of the 19th JCT traffic signal symposium \& exhibition. JCT Consulting Ltd., University of Warwick. Available at: http:/www. jetconsultancy.co.uk/Symposium/Symposium2014/ PapersForDownload/A\%20Review\%20 of\%20 SCATS \%20Operation \%20and\%20Deployment $\% 20$ in\%20Dublin.pdf (accessed 8 June 2017).
MacLaran A and Kelly S (eds) (2014) Neoliberal Urban Policy and the Transformation of the City. Basingstoke: Palgrave Macmillan.

McLaren D and Agyeman J (2015) Sharing Cities: A Case for Truly Smart and Sustainable Cities (Urban and Industrial Environments). Cambridge, MA: MIT Press.

McNeill D (2015) Global firms and smart technologies: IBM and the reduction of cities. Transactions of the Institute of British Geographers 40(4): 562-574.

Moore NM (2007) Valorizing urban heritage? Redevelopment in a changing city. In: Moore NM and Whelan Y (eds) Heritage, Memory and the Politics of Identity: New Perspectives on the Cultural Landscape. Aldershot and Burlington, VT: Ashgate, pp. 95-108.

Moore-Cherry $\mathrm{N}$ and Vinci I (2012) Urban regeneration and economic crisis: past development and future challenges in Dublin, Ireland. Planum - The Journal of Urbanism 25(2): 1-16.

Panchanathan S, Chakraborty S, McDaniel T, Bunch M, O'Connor N, Little S, McGuinness K and Marsden M (2016) Smart stadium for smarter living: enriching the fan experience. In: 2016 IEEE international symposium on multimedia (ISM), 2016, pp. 152157. IEEE. Available at: http://ieeexplore.ieee.org/ abstract/document/7823604/ (accessed 7 June 2017).

Sadowski J and Pasquale FA (2015) The spectrum of control: a social theory of the smart city. First Monday 20. Available at: https://papers.ssrn.com/sol3/papers. cfm?abstract_id=2653860 (accessed 24 April 2017).

Shelton T, Zook M and Wiig A (2015) The 'actually existing smart city'. Cambridge Journal of Regions, Economy and Society 8(1): 13-25.

Shin H, Park SH and Sonn JW (2015) The emergence of a multiscalar growth regime and scalar tension: the politics of urban development in Songdo New City, South Korea. Environment and Planning C: Government and Policy 33(6): 1618-1638.

Shwayri ST (2013) A model Korean ubiquitous eco-city? The politics of making Songdo. Journal of Urban Technology 20(1): 39-55.

Smart Dublin (2018) What is Smart Dublin? Available at: http://smartdublin.ie/about/ (accessed 17 May 2018).

Söderström O, Paasche T and Klauser F (2014) Smart cities as corporate storytelling. City 18(3): 307-320.

Townsend AM (2013) Smart Cities: Big Data, Civic Hackers, and the Quest for a New Utopia. 1st ed. New York, NY: W.W. Norton.

Vanolo A (2014) Smartmentality: The smart city as disciplinary strategy. Urban Studies 51(5): 883-898.

Wiig A (2016) The empty rhetoric of the smart city: from digital inclusion to economic promotion in Philadelphia. Urban Geography 37(4): 535-553. 